This item was submitted to Loughborough's Research Repository by the author.

Items in Figshare are protected by copyright, with all rights reserved, unless otherwise indicated.

\title{
Effects of wind and clothing apertures on local clothing ventilation rates and thermal insulation
}

PLEASE CITE THE PUBLISHED VERSION

http://dx.doi.org/10.1177/0040517513512399

\section{PUBLISHER}

Sage Publications Ltd / ( T The authors

VERSION

AM (Accepted Manuscript)

\section{PUBLISHER STATEMENT}

This work is made available according to the conditions of the Creative Commons Attribution-NonCommercialNoDerivatives 4.0 International (CC BY-NC-ND 4.0) licence. Full details of this licence are available at: https://creativecommons.org/licenses/by-nc-nd/4.0/

\section{LICENCE}

CC BY-NC-ND 4.0

\section{REPOSITORY RECORD}

Ke, Ying, George Havenith, Xianghui Zhang, Xiaohui Li, and Jun Li. 2019. "Effects of Wind and Clothing Apertures on Local Clothing Ventilation Rates and Thermal Insulation". figshare.

https://hdl.handle.net/2134/16171. 


\section{Effects of wind and clothing apertures on local clothing ventilation rates and thermal insulation}

Ying $\mathrm{Ke}^{1,2}$, Xianghui Zhang ${ }^{1,2}$, Xiaohui $\mathrm{Li}^{1,2}$ and Jun $\mathrm{Li}^{1,2}$

${ }^{1}$ Protective Clothing Research Center, Fashion Institute, Donghua University, Shanghai, P.R. China

${ }^{2}$ Key Laboratory of Clothing Design and Technology, Ministry of Education, Shanghai, P.R. China

Corresponding author:

Jun Li, Protective Clothing Research Center, Fashion Institute, Donghua University, NO. 1882, West Yan-an Road, Shanghai 200051, P.R. China

Email: lijun@dhu.edu.cn

\section{Abstract}

The purpose of this study was to investigate the effects of wind $(0 \mathrm{~m} / \mathrm{s}, 1.1 \mathrm{~m} / \mathrm{s})$ and clothing apertures (no close, close hem, close hem and neck) and the combined effects of them on local clothing ventilation rates and localized thermal insulation. Nine working jackets with identical design but different garment sizes and fabric permeability were made. The results showed that wind and clothing apertures had distinct effects both on the local ventilation rates and the local thermal insulation. The local ventilation rates of the right arm were largest at $1.1 \mathrm{~m} / \mathrm{s}$ wind speed with clothing hem closed. Chest and back ventilation rates were higher at wind than at no wind. Closing garment hem affected the local thermal insulation of the impermeable garments mostly. 
Except for wind and garment apertures, garment sizes and fabric permeability also impacted the local ventilation rates and the thermal insulation.

\section{Keywords}

Wind, garment aperture, local ventilation rates, local thermal insulation

\section{Introduction}

Clothing thermal insulation (TI) and ventilation rates (VR) were two important parameters affecting its heat and mass transfer properties, and then affecting heat and moisture comfort. Both the two parameters are impacted by: fabric properties, garment design, garment sizes, body postures and environmental conditions. Among these, wind and garment apertures were two important factors.

Two tracer gas methods have already been developed and applied widely to measure clothing VR. One was developed by Crockford et al(CR). The CR method needed to measure the clothing microclimate volume and the air exchange rate. ${ }^{1}$ The other method was developed by Lotens and Havenith(LH). Compared to the CR method, the LH method was easier to be implemented, as it didn't need to measure the clothing microclimate volume. ${ }^{2}$ Many other ventilation measuring systems were built based on the two basic methods. ${ }^{3-7}$

Considerable work has been carried out for studying the impacts of wind and garment apertures on garment TI and VR. ${ }^{3-5,8-11}$ Havenith et al. studied the effects of wind on ventilation and found that wind impacted clothing ventilation significantly. ${ }^{3,4}$ And later Havenith et. al. corrected the thermal insulation model according to the effects of wind and walking. ${ }^{12}$ Ueda et al. investigated the 
influence of a back opening on the ventilation of rainwear and recognized that the effect of aperture on clothing ventilation depended strongly on wind the wearer's movement. ${ }^{11}$ Ueda and Havenith discussed the effects of neck and wrist openings on ventilation and found that the suits with collars and cuffs open showed greater ventilation. But the effects were different according to different fabric permeabilities. ${ }^{10}$

Most of the studies above mainly focused on the whole garment ventilation and thermal insulation. Human body parts are different in physical characteristics. And the related regional microclimate conditions under clothing also differ from each other. These all lead to the regional differences both in clothing local TI and local VR. Some work has been done with regard to the local VR.,

${ }^{13}$ Ueda et al. compared the local VR of 5 diapers between different locations. And the Lotens and Havenith (LH)'s steady-state method was adopted to measure the clothing VR. They found that the ventilation of the upper site contributed heavily to the overall ventilation. ${ }^{2,3,6}$ Ueda et al. used the Crocford's unsteady state method to investigate the regional VR of several working jackets. They proposed that the clothing ventilation should be measured in different body regions in response to the regional sweat rates. ${ }^{10,13,14}$ However, neither of the studies considered the effects of wind and garment apertures and the combined effects of them on local VR. In addition, the garment local thermal properties have also attracted some attention. ${ }^{15,}{ }^{16}$ However, there is also lack of investigation on effects of wind and garment apertures on local TI, although they are essential for clothing design and thermal comfort assessment. Ho et al. added the fullness of chest and back of T-shirt and investigated the effects of wind on thermal insulation. But they only focused on the whole garment thermal insulation. ${ }^{17}$

The focus of this study was to explore the effects of wind and clothing apertures on the local VR 
of three garment locations- the right arm, the chest, the back, and on the local TI of two garment locations - the right arm, the chest\&back, of 9 working jackets. The jackets were identical in design but different in sizes and fabric permeability. First, the local VR of three garment regions were measured using a ventilation measuring system developed based on the LH's steady-state method. ${ }^{2,3}$ Second, the local TI values of two garment regions were measured using a standing thermal manikin. The local VR and TI in two wind speed levels $(<0.3 \mathrm{~m} / \mathrm{s}, 1.1 \mathrm{~m} / \mathrm{s})$ and three garment aperture closing conditions (no close, close hem, close hem\&neck) were measured separately. The aim was to give suggestions on garment apertures design and thermal comfort assessment for clothing designers and on choosing suitable garments for end users.

\section{Materials and methods}

\section{Fabric}

Three $100 \%$ cotton fabrics with the same thickness $(0.48 \mathrm{~mm})$ and fabric weave (twill) but different air permeability—permeable (PM), semi-permeable (SM), impermeable (IM) were chosen. The fabrics were half bleached. The IM fabric was the SM fabric laminated with an impermeable thin coating. Table 1 shows the basic characteristics of the three fabrics.

Table 1. Details of the experimental fabrics

\begin{tabular}{|c|c|c|c|c|c|c|c|}
\hline \multirow{4}{*}{ Sample } & Warp & Weft & \multirow{3}{*}{ Weight } & \multirow{3}{*}{$\begin{array}{l}\text { Thermal } \\
\text { resistance }\end{array}$} & \multirow{3}{*}{$\begin{array}{l}\text { Vapor } \\
\text { resistance }\end{array}$} & \multirow{3}{*}{$\begin{array}{l}\text { Air } \\
\text { permeability }\end{array}$} & \multirow{3}{*}{$\begin{array}{l}\text { Drape } \\
\text { coefficient }\end{array}$} \\
\hline & & & & & & & \\
\hline & density & density & & & & & \\
\hline & $(/ \mathrm{cm})$ & $(/ \mathrm{cm})$ & $\left(\mathrm{g} / \mathrm{m}^{2}\right)$ & $\left({ }^{\circ} \mathrm{C} \cdot \mathrm{m}^{2} / \mathrm{W}\right)$ & $\left(\mathrm{Pa} \cdot \mathrm{m}^{2} / \mathrm{W}\right)$ & $(\mathrm{mm} / \mathrm{s})$ & (\%) \\
\hline PM & 31 & 22 & 186.30 & 0.0162 & 2.80 & 135.18 & 89.90 \\
\hline SM & 40 & 22 & 233.14 & 0.0096 & 3.15 & 59.00 & 88.43 \\
\hline
\end{tabular}


PM: permeable; SM: semi-permeable; IM: impermeable

\section{Experimental garment}

Working jackets with three different sizes $(170,175,180$ - height, $\mathrm{cm})$ were made using the three fabrics above respectively. The sizes were decided according to the Chinese standard-GB/T 1335.1-1997. ${ }^{18}$ Overall, 9 experimental garments were made: 170-PM (G1), 170-SM (G2), 170-IM (G3), 175-PM (G4), 175-SM (G5), 175-IM (G6), 180-PM (G7), 180-SM (G8) and 180-IM

(G9). Figure 1 shows the style chart of the experimental jacket.

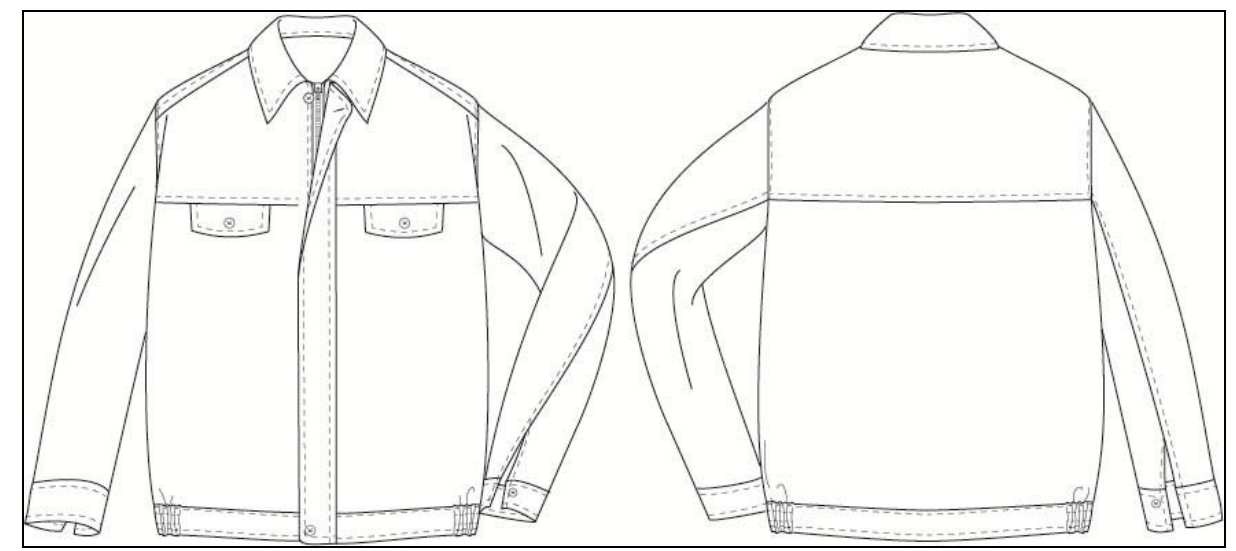

(a)

(b)

Figure 1. The style chart of the experimental garment. (a) front view; (b) back view.

\section{Measurement of the local VR}

The steady-state method was adopted to measure the local clothing ventilation, as originally described by Lotens and Havenith, and further developed by Havenith et al. ${ }^{2,3}$

Figure 2 shows the photos of the ventilation measuring system used in this study. The system has two improvements compared to the LH's system. First, the system can measure the local VR of the chest, the back, the right arm and the left arm simultaneously or separately. Second, four tracer gas analyzers were used during testing. This decreased the testing time and improved the 
measuring precision.

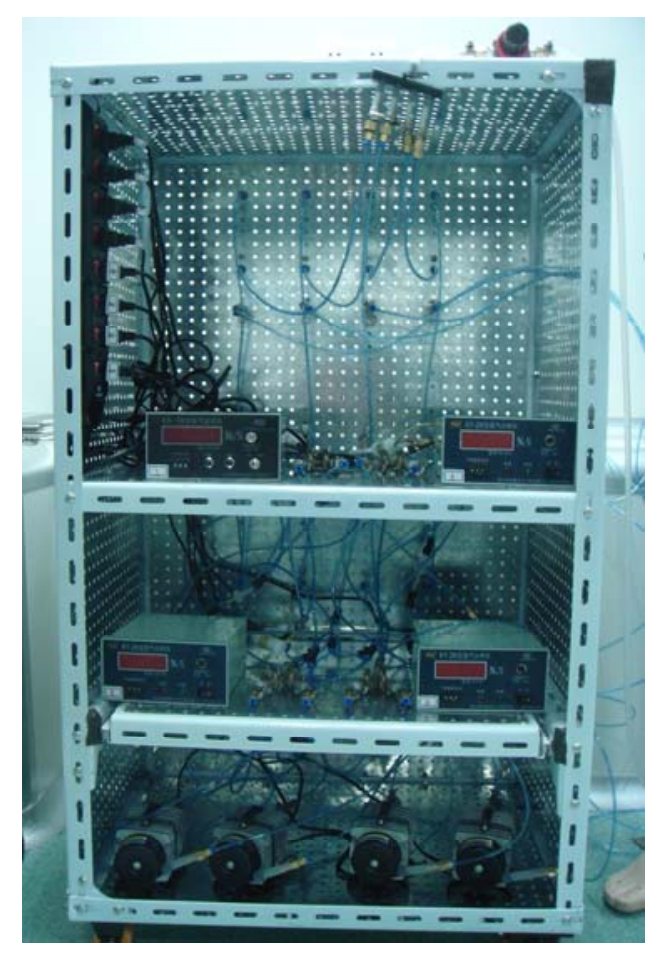

(a)

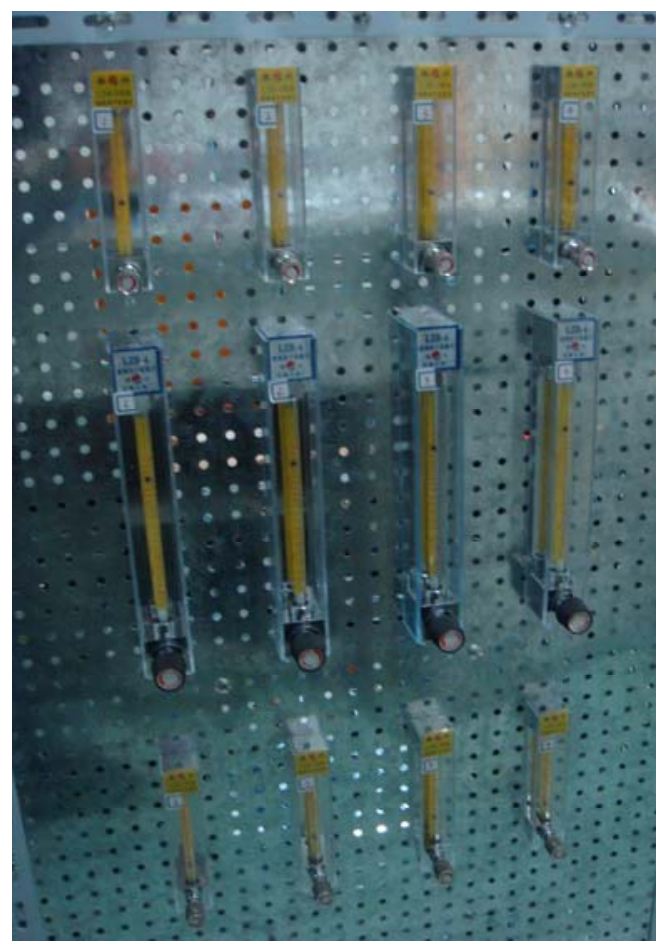

(b)

Figure 2. The photographs of the local ventilation system. (a) front view; (b) back view.

$\mathrm{N}_{2}$ was chosen as the tracer gas. A $\mathrm{N}_{2}$ analyzer (KN-99, China) was used to measure the $\mathrm{N}_{2}$ concentration of the outlet and inlet flow. The analyzer was calibrated with pure air and pure $\mathrm{N}_{2}$ before each testing. The clothing local VR are computed according to Equation (1).

$$
\text { Vent }_{i}=\mathrm{FR}_{i} \times \frac{C_{\text {in }, i}-C_{\text {out }, i}}{C_{\text {out }, i}-C_{\text {air }, i}}
$$

Where i stands for the different garment locations, from 1 to 4 , FR is the flow rate of the local circulating system (L/min), $\mathrm{C}_{\mathrm{in}}$ is the $\mathrm{N}_{2}$ concentration of the inlet flow (\%), $\mathrm{C}_{\text {out }}$ is the $\mathrm{N}_{2}$ concentration of the outlet flow, that is the $\mathrm{N}_{2}$ concentration under the local microclimate (\%), $\mathrm{C}_{\text {air, }}$ is the $\mathrm{N}_{2}$ concentration of the air around the ith clothed body (\%). 
The whole measuring system includes two parts: the main flow and the sampling flow. The main flow makes a circulation under the clothing local microclimate. And the sampling flow is used for inlet and outlet flow sampling for $\mathrm{N}_{2}$ concentration measurement. Usually, the sampling flow rate is less than $5 \%$ of the main flow to reduce the effects of the sampling process on the whole circulation. In this system, the main flow is about $2.2 \mathrm{~L} / \mathrm{min}$, and the sampling flow is controlled below $0.1 \mathrm{~L} / \mathrm{min}$. Pure $\mathrm{N}_{2}$ (flow rate about $0.2 \mathrm{~L} / \mathrm{min}$ ) is injected to the main flow to fully mix with the air pumping from the clothing microclimate. During the ventilation measurement, the air renewal system in the testing room was opened after each testing (about 30 minutes) for about 10 minutes to prevent the buildup of $\mathrm{N}_{2}$.

\section{Measurement of the clothing local TI}

A non-evaporative thermal manikin (FDT11) with 11 separate segments was employed to do thermal insulation measurement. ${ }^{19,20}$ The manikin is $1.70 \mathrm{~m}$ tall and its surface area is $1.68 \mathrm{~m}^{2}$. As the limitations of the manikin, the chest and back were taken as one segment. According to ISO 9920, the manikin was positioned in an air conditioned chamber with $20 \pm 1^{\circ} \mathrm{C}, 50 \pm 5 \%$ relative humidity and $<0.3 \mathrm{~m} / \mathrm{s}$ air flow. The skin temperature of the manikin was set at $35^{\circ} \mathrm{C}$. ${ }^{21}$ Two reasons were considered when determining the environmental temperature: one was the real wearing temperature $\left(15-20^{\circ} \mathrm{C}\right)$ of the experimental garments. And the other was that the calibration temperature of the flow meters was $20^{\circ} \mathrm{C}$. At this temperature, they have the highest measuring precision. Two air speed levels were studied, no wind (air flow $<0.3 \mathrm{~m} / \mathrm{s}$ ) and $1.1 \mathrm{~m} / \mathrm{s}$ headwind. To investigate the effects of clothing apertures' close or open conditions on the local VR and the local TI, three aperture closing conditions were studied: apertures under normal wearing conditions (no close), closing garments' hem (close hem), closing garments' hem and 
neck (close hem\&neck). A rubber band was used to close garment apertures. A pilot testing showed that the local VR and TI were changed non-significantly when closing neck only compared with those at no close. So this condition was not considered in this study. Therefore, 6 conditions (two wind conditions $\times$ three garment aperture conditions) were tested for each garment. Each testing repeated 3 times. The manikin was redressed between repeat measurements. Thermal insulation of the boundary air layer was also measured. Considering the real wear situation of the experimental jackets, a 100\%-cotton, long sleeve underwear was put on before the jacket. And the air condition of the manikin wearing the underwear was taken as the boundary air layer. Figure 3 (a) shows the thermal manikin with the tracer gas tubing system. Figure 3 (b) shows the thermal manikin wearing the experimental jacket with neck and hem closed.

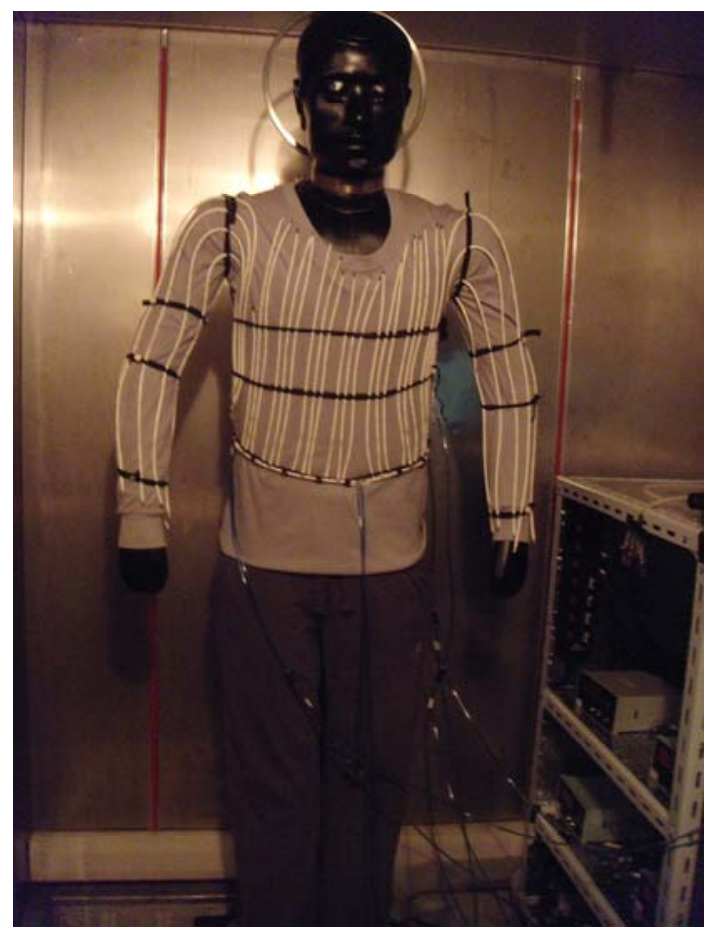

(a)

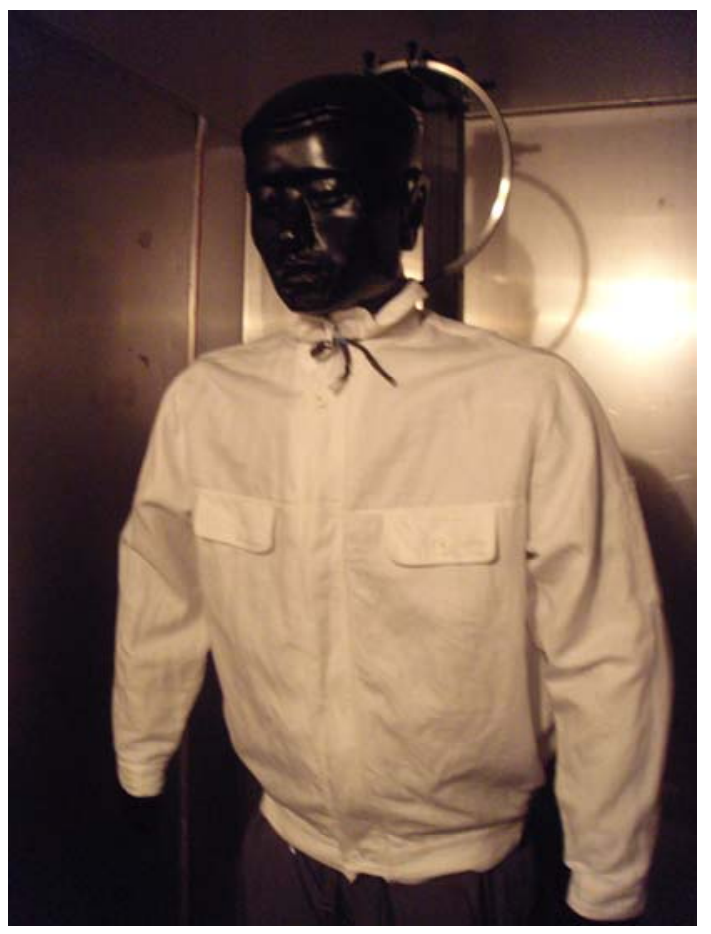

(b)

Figure 3. The thermal manikin and the tubing setup of the ventilation system. (a) the thermal manikin with the tubing setup; (b) the thermal manikin and the experimental jacket with neck and hem closed.

\section{Statistics}

SPSS (Version 18.0) was used to do data analysis. A 3 way-repeated ANOVA was conducted to 
identify significant effects of the wind, garment aperture, fabric permeability, garment size and garment location on local VR and TI. Post-hoc tests were conducted to examine the multiple comparisons of these factors. As the equal variances were assumed, Scheffe method was used to do post hoc testing. P-value $<0.05$ indicated statistical significance.

\section{Results and discussion}

As the thermal manikin and the experimental jackets can be assumed as bilateral symmetry, the local TI and VR of the right arm equals the left arm's. Therefore, it was only need to measure the local VR of three garment locations: right arm/left arm, the chest and the back.

\section{The local VR}

Table 2 shows the clothing local VR of the right arm, the chest and the back of the 9 experimental jackets at different wind and garment aperture conditions. The local VR of the experimental jackets were consistent with the previous studies of similar garments. ${ }^{13,22}$

Significant effects of garment size $(\mathrm{p}<0.001)$, fabric permeability $(\mathrm{p}<0.001)$, wind speed $(\mathrm{p}<0.001)$, garment apertures $(\mathrm{p}<0.001)$ and locations $(\mathrm{p}<0.001)$ were observed according to ANOVA analysis. The larger of the p value, the more significant effect on the local VR. Post hoc testing indicated that for garment size conditions, the local VR were significantly different except size 170 and 175 . For fabric permeability conditions, the local VR were all significantly different $(\mathrm{p}<0.05)$. For wind conditions, the local VR were also significantly different $(\mathrm{p}<0.001)$. For garment aperture closing conditions, the local VR were significantly different except no close and closing hem\&neck. For location conditions, the local VR were all significantly different $(\mathrm{p}<0.001)$. The interactions of these factors were also statistically significant. 
Table 2. The local ventilation rates at different wind speeds and garment aperture conditions. Values are mean \pm SD.

\begin{tabular}{|c|c|c|c|c|c|c|c|}
\hline \multirow{2}{*}{\multicolumn{2}{|c|}{ Garmen }} & \multicolumn{6}{|c|}{ Local VR (L/min) } \\
\hline & & & & 0-hem & 1.1-hem & 0-hem\&neck & 1.1-hem\&neck \\
\hline $\mathrm{t}$ & Location & 0-no close & 1.1-no close & closed & closed & closed & closed \\
\hline G1 & & $10.62 \pm 0.23$ & $20.93 \pm 0.12$ & $16.23 \pm 0.83$ & $21.19 \pm 1.03$ & $13.74 \pm 0.41$ & $10.23 \pm 0.60$ \\
\hline G2 & & $10.2 \pm 0.02$ & $13.46 \pm 0.37$ & $22.13 \pm 0.43$ & $41.30 \pm 1.55$ & $15.78 \pm 0.84$ & $24.17 \pm 1.34$ \\
\hline G3 & & $1.55 \pm 0.12$ & $2.83 \pm 0.27$ & $1.68 \pm 0.14$ & $2.59 \pm 0.09$ & $1.78 \pm 0.13$ & $2.17 \pm 0.11$ \\
\hline G4 & & $11.23 \pm 1.05$ & $11.05 \pm 0.57$ & $12.15 \pm 1.81$ & $22.14 \pm 1.22$ & $23.80 \pm 0.18$ & $21.11 \pm 2.12$ \\
\hline G5 & & $12.60 \pm 0.04$ & $17.03 \pm 0.07$ & $14.51 \pm 0.34$ & $22.75 \pm 0.67$ & $15.94 \pm 0.43$ & $22.15 \pm 0.45$ \\
\hline G6 & & $1.84 \pm 0.09$ & $3.31 \pm 0.17$ & $2.46 \pm 0.16$ & $4.11 \pm 0.14$ & $2.90 \pm 0.18$ & $3.72 \pm 0.29$ \\
\hline G7 & & $12.37 \pm 0.26$ & $25.44 \pm 0.54$ & $10.97 \pm 0.26$ & $37.65 \pm 14.93$ & $10.50 \pm 0.30$ & $23.49 \pm 0.94$ \\
\hline G8 & Right & $15.57 \pm 2.11$ & $18.01 \pm 0.45$ & $13.03 \pm 2.73$ & $40.71 \pm 1.06$ & $12.08 \pm 0.56$ & $21.53 \pm 0.93$ \\
\hline G9 & arm & $2.14 \pm 0.11$ & $4.22 \pm 0.18$ & $2.06 \pm 0.20$ & $6.69 \pm 0.54$ & $2.33 \pm 0.09$ & $2.71 \pm 0.18$ \\
\hline G1 & & $22.73 \pm 1.04$ & $36.30 \pm 6.57$ & $41.69 \pm 0.48$ & $39.5 \pm 2.26$ & $47.17 \pm 2.27$ & $13.90 \pm 0.73$ \\
\hline G2 & & $12.20 \pm 0.45$ & $8.8 \pm 0.10$ & $20.35 \pm 0.52$ & $36.54 \pm 1.66$ & $11.73 \pm 0.52$ & $24.03 \pm 3.13$ \\
\hline G3 & & $17.24 \pm 0.77$ & $25.01 \pm 1.65$ & $13.88 \pm 0.08$ & $14.95 \pm 0.74$ & $10.42 \pm 0.85$ & $39.42 \pm 3.66$ \\
\hline G4 & & $21.41 \pm 1.31$ & $11.37 \pm 1.07$ & $21.11 \pm 2.07$ & $36.99 \pm 3.60$ & $20.77 \pm 0.52$ & $20.29 \pm 0.69$ \\
\hline G5 & & $17.80 \pm 1.23$ & $54.01 \pm 2.07$ & $25.19 \pm 0.51$ & $54.08 \pm 1.22$ & $10.46 \pm 1.26$ & $24.41 \pm 0.53$ \\
\hline G6 & & $16.44 \pm 1.42$ & $24.88 \pm 1.17$ & $16.69 \pm 0.74$ & $34.24 \pm 2.40$ & $13.05 \pm 0.44$ & $14.23 \pm 1.17$ \\
\hline G7 & Chest & $16.50 \pm 0.35$ & $51.40 \pm 1.57$ & $13.93 \pm 0.49$ & $47.34 \pm 2.47$ & $13.90 \pm 0.38$ & $44.80 \pm 2.14$ \\
\hline
\end{tabular}




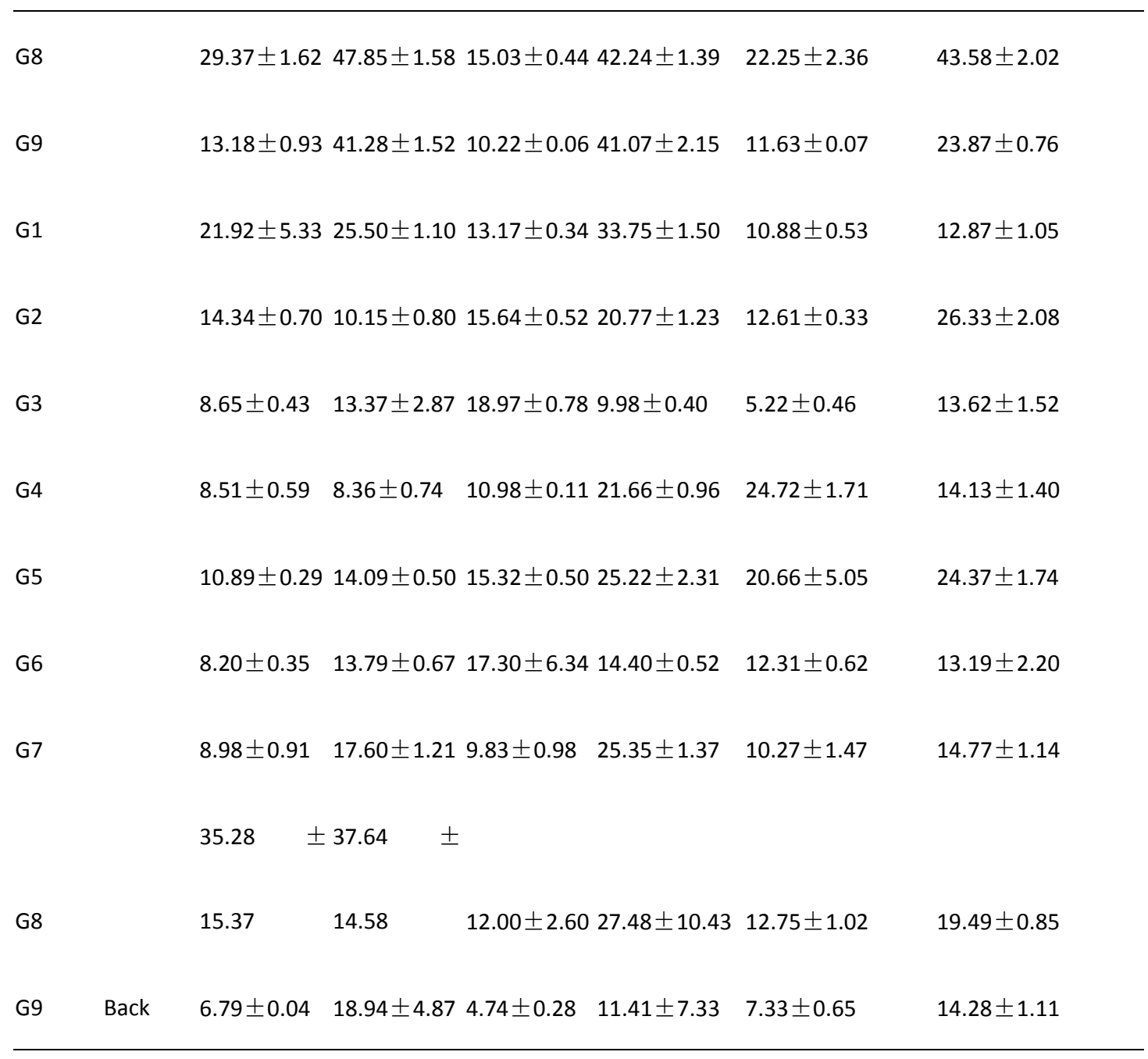

G1: 170-PM; G2: 170-SM; G3: 170-IM; G4: 175-PM; G5: 175-SM; G6: 175-IM; G7-180-PM; G8: 180-SM; G9: 180-IM

\section{The local TI}

Figure 4 shows the local TI of the chest\&back and the right arm of the 9 experimental garments at different wind and garment aperture conditions. The TI was the total thermal insulation of the garment section. The local TI of the experimental garments were consistent with the previous study of similar jackets. ${ }^{22}$

Overall, the effects of garment size, fabric permeability, wind, garment apertures and locations on the local TI were significant $(\mathrm{p}<0.05, \mathrm{p}<0.05, \mathrm{p}<0.001, \mathrm{p}<0.001, \mathrm{p}<0.001)$. The interactions of these factors were also significant except between permeability and wind $(\mathrm{p}=0.053)$. The TI 
between the chest\&back and the right arm differed significantly $(\mathrm{p}<0.001)$. Post hoc testing on different garment sizes comparisons showed that the local TI values were not significantly different. For the fabric permeability condition, the local TI were significantly different $(p<0.05)$ except garments SM and IM. For the wind speed condition, the local TI were also significantly different $(\mathrm{p}<0.001)$. For the garment aperture condition, the local TI values were significantly different except no close and close hem.

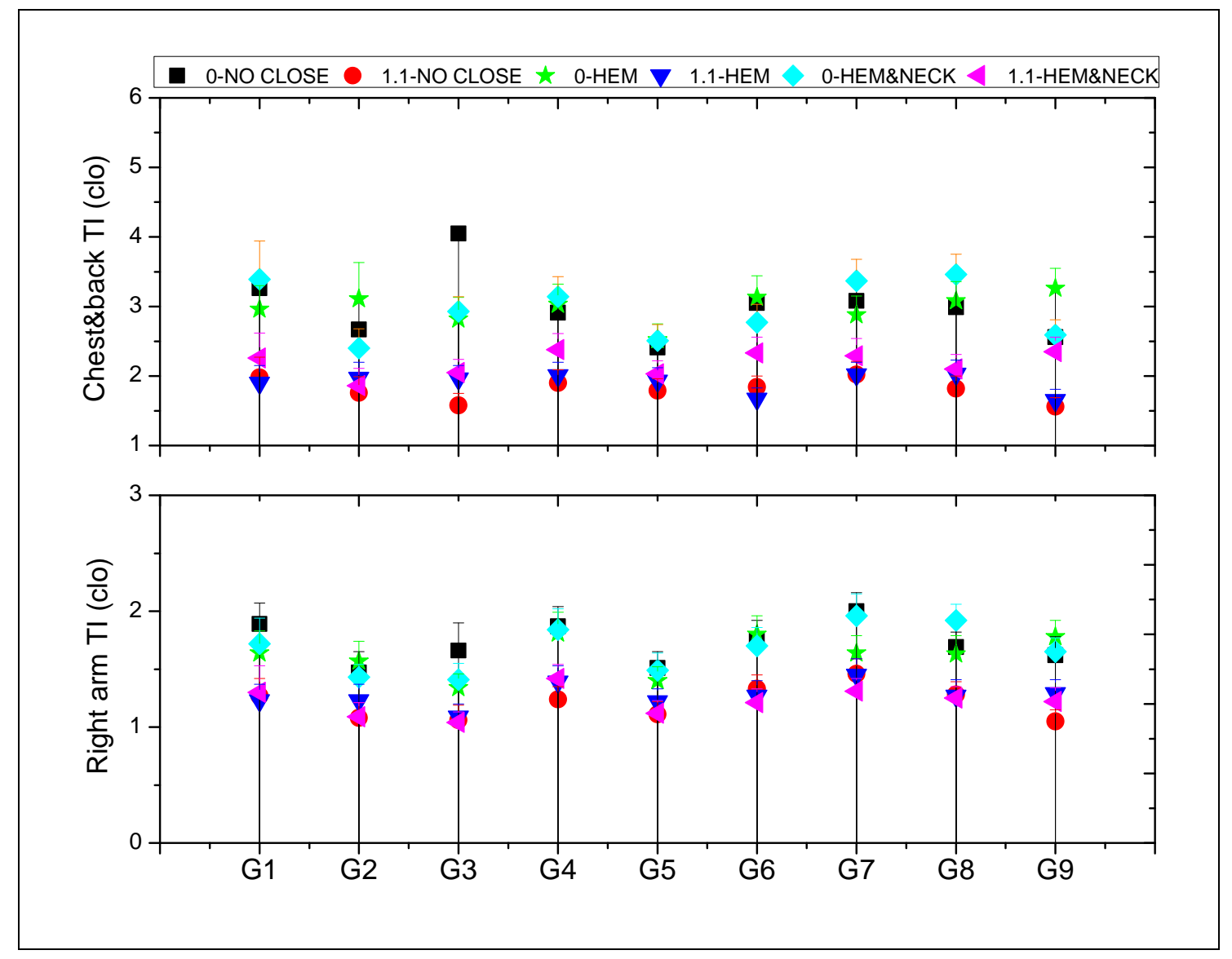

Figure 4. The local TI of the 9 jackets at different wind and aperture conditions. Values are mean+SD.

G1: 170-PM; G2: 170-SM; G3: 170-IM; G4: 175-PM; G5: 175-SM; G6: 175-IM; G7-180-PM; G8: 180-SM; G9:

180-IM; TI: thermal insulation 
Effects of wind on the local VR. For local VR of the right arm (Figure 5(a)), wind increased the local VR significantly. This was consistent with the wind effects on whole garment ventilation. ${ }^{3}$ In addition, it was obvious that the right arm VR of the IM garments were the smallest. Garments of size 180 had the largest VR. But it was interesting that for PM garments, the right arm VR of size 175 was smaller than size 170 at $1.1 \mathrm{~m} / \mathrm{s}$ wind. The possible reason was that the wind decreased the microclimate volume of the right arm except for increasing the air exchange through fabric. And the effects of wind on decreasing the right arm microclimate volume were stronger than it on increasing the air exchange.

Figure 5(b) presents the chest VR at different conditions. The chest VR were obviously larger than those of the right arm. Wind increased the chest VR except G4. This may also be caused by the interactions between decreased the local microclimate volume and increased the air exchange through fabric. For G4, the former affected more. The IM garments also had the smallest VR. It looked strange that the G5 had the largest chest VR. The reason was that, for the thermal manikin we used, the upper body forward about $12.5^{\circ}$. And this increased the front hem of the garments. The G5 had bigger front hem than garments 180 and G4.

Back VR at different wind speeds were shown in Figure 5(c). The local VR were smallest at $<0.3$ $\mathrm{m} / \mathrm{s}$ except G2. The reason may be that, although wind increased the back microclimate volume, the air in chest was pushed to the back. The tracer gas concentration under back microclimate increased, accompanied by the back microclimate volume increased. For G2, the former affected more. The back VR of the IM garments were also the smallest. The G8 had the largest back VR. This may be caused by the fabric drapability, which caused the bigger microclimate volumes for the SM garments than these of the PM garments. 
In conclusion, the effects of wind on the local VR were different according to different garment sizes and fabric permeability. The local VR were not positive correlated with the garment size. For the effects of fabric permeability, it was obvious that the IM garments had the smallest local VR. But for PM and SM garments, the local VR were not directly correlated to fabric permeability. It was also affected by the fabric drapability.
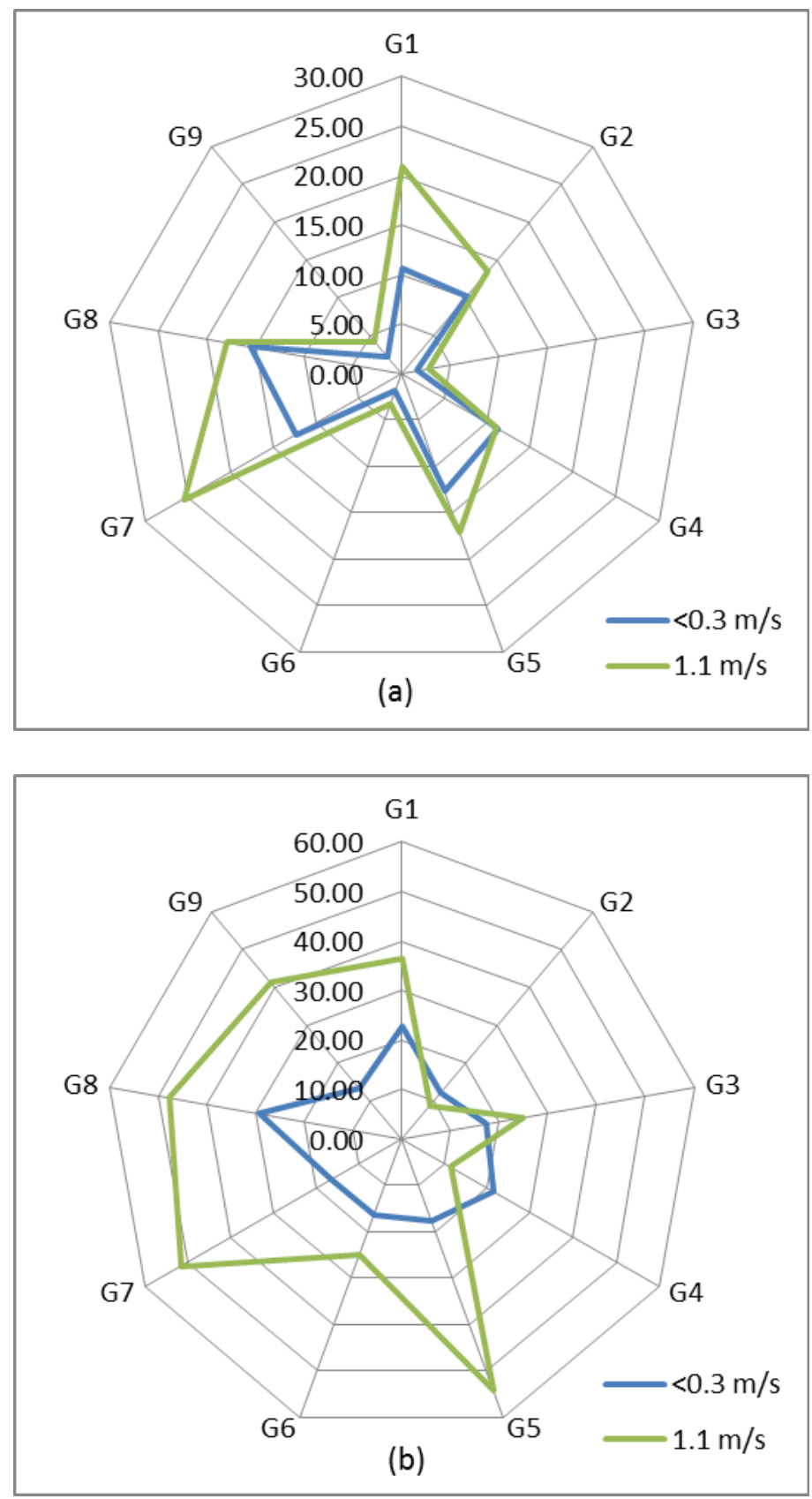


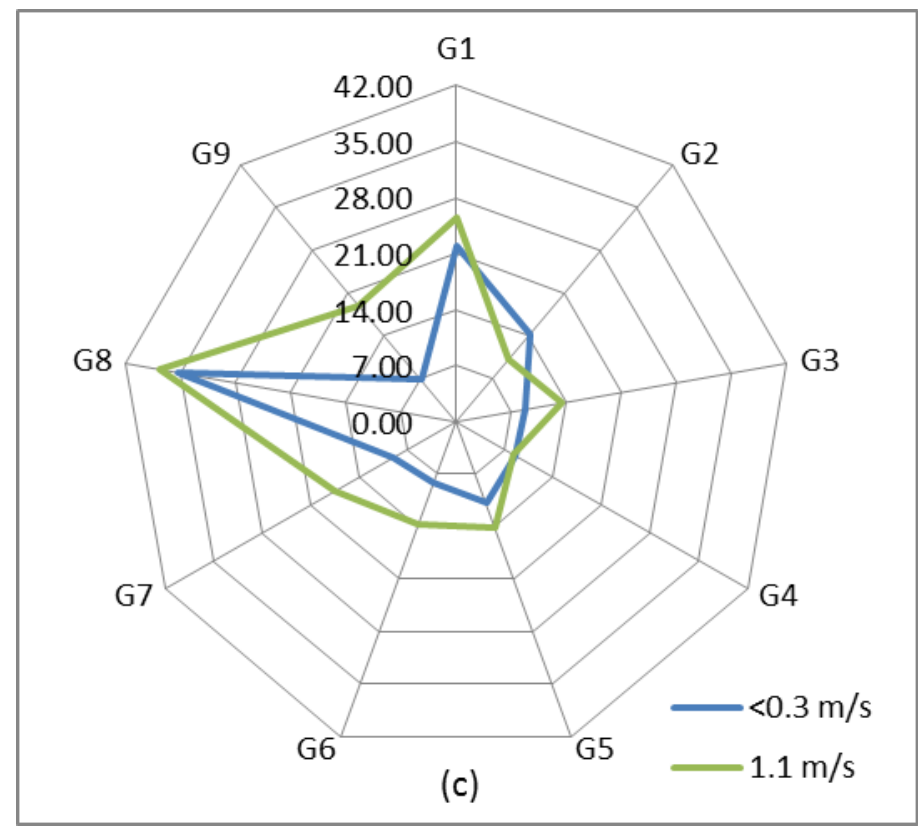

Figure 5. The local VR of the right arm (a), chest (b) and back (c) of the 9 experimental garments at different wind

conditions.

G1: 170-PM; G2: 170-SM; G3: 170-IM; G4: 175-PM; G5: 175-SM; G6: 175-IM; G7-180-PM; G8: 180-SM; G9:

180-IM; VR: ventilation rates

Effects of wind on the local TI. Figure 6 shows the chest\&back and the right arm TI of the 9 experimental jackets at different wind conditions. It was obvious that wind decreased the local TI. Garments 170 had the largest local TI. Garments 180 had higher TI than 175 except the IM garments. It was interesting that for garments 170 and 175 at $<0.3 \mathrm{~m} / \mathrm{s}$ wind, the IM garments had the largest TI, followed by PM garments. While for garments 180, the IM garment had the smallest local TI. For chest\&back TI at $1.1 \mathrm{~m} / \mathrm{s}$ wind, the situations were much different. The PM garments had the largest TI, followed by the SM garments and IM garments.

For the local TI of the right arm, wind also decreased the local TI significantly. The 180 garments had the largest local TI except the IM garments. For IM garments, size 175 had the largest TI, 
followed by garments 170 and 180 . This may be caused by the complicated regional microclimate conditions of the right arm. ${ }^{23,24}$

Therefore, it can be concluded that the effects of wind on the local TI were also impacted by garment sizes and fabric permeability. The local TI was positive correlated with the garment sizes except the IM garments. The IM garments had bigger microclimate volumes than the PM and SM garments because of the fabric drapability. This may give us some suggestions that when choosing working jacket, people should not only pay attention to the garment size, but also to the fabric properties, especially when choosing garments of big size.
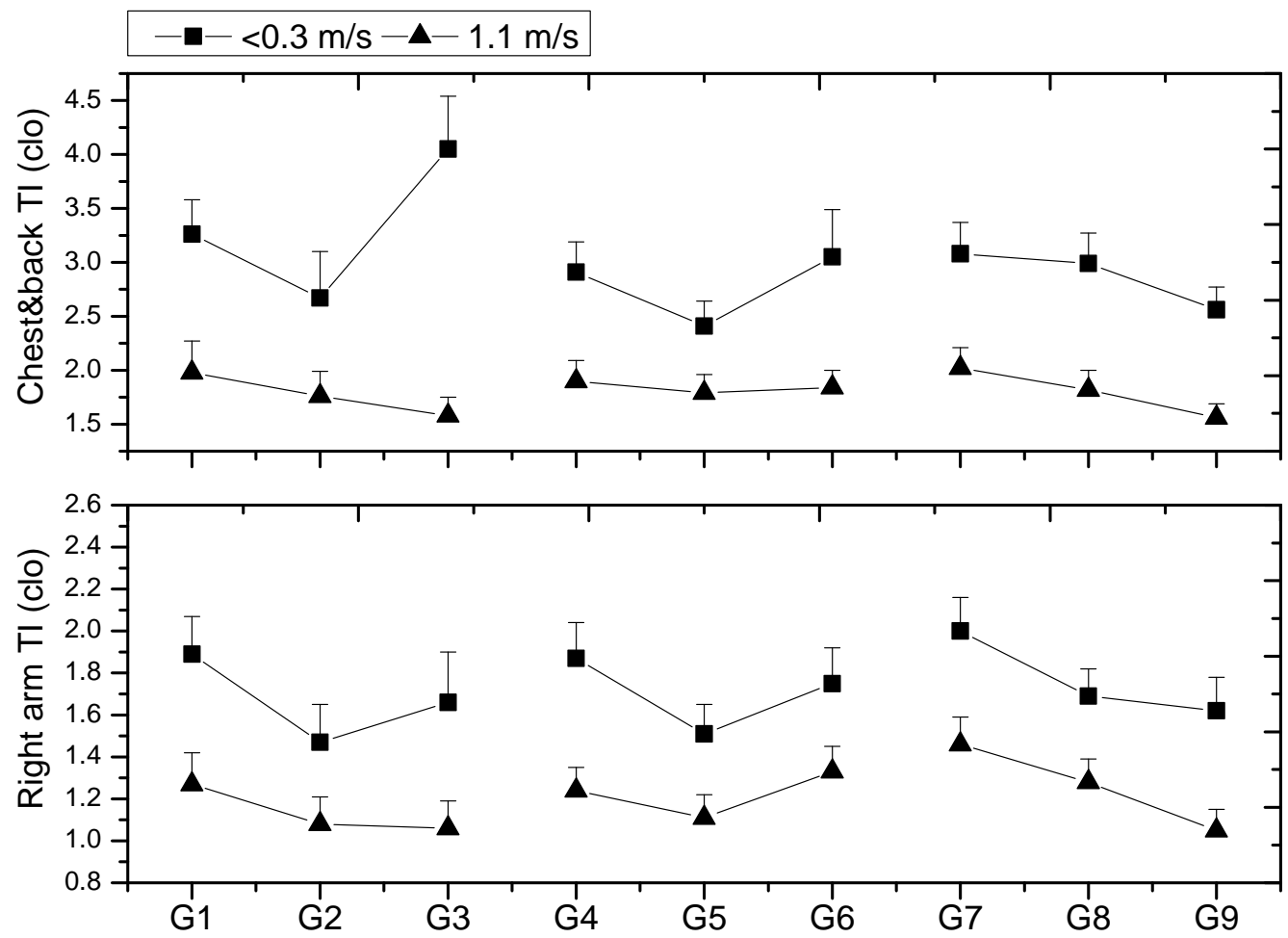

Figure 6. The local TI of the chest\&back and the right arm of the experimental jackets at different wind conditions. 


\section{Effects of clothing apertures}

Effects of clothing apertures on the local VR. Figure 7 presents the local VR of the 9 jackets at different garment aperture closing conditions.

For the right arm (Figure 7(a)), the local VR increased for garments 170 and 175 at close hem only or close hem\&neck, compared with the local VR at no close. While for garments 180, the VR decreased when closing garment apertures especially at close hem. The relative decrease rates were: for G7, the decrease rates when closing hem and hem\&neck were $11.3 \%$ and $15.1 \%$, for G8 were $17 \%$ and $23.1 \%$, for G9 were $3.7 \%$ when closing hem only. Therefore, it can be concluded that for garments 180, partial air exchange of the right arm was through garment hem or neck. And the effects of closing apertures on the right arm VR were also impacted by garment sizes and fabric permeability.

Figure 7(b) shows the chest VR of the 9 experimental jackets at different garment aperture conditions. For garments 170, the VR of G1 increased significantly at close hem and close hem\&neck. For G2, the local VR increased at close hem while it decreased at close hem\&neck. For G3, the VR decreased at hem or close hem\&neck. While for garments 175, the local VR decreased $1.4 \%$ and 3.0\% at close hem and close hem\&neck of G4. The local VR increased when closing hem but it decreased when closing hem\&neck for G5. The local VR increased 1.5\% at close hem but it decreased $20.6 \%$ at close hem\&neck of G6. For garments 180, the local VR decreased at close hem or close hem\&neck. And for G8 and G9, the chest VR increased at close hem\&neck compared with the local VR at close hem only. In conclusion, closing garment apertures impacted the chest VR significantly. And the chest VR at different garment apertures 
were impacted by garment sizes and fabric permeability.

The back VR at different aperture closing conditions were illustrated in Figure 7(c). For garments 170, the VR decreased when closing garment apertures except at close hem for G2. For garments 175, the VR increased when closing garment apertures. While for garments 180, the VR increased when closing garment hem or neck for G7. But for G8, the back VR decreased about $65.9 \%$ and 63.9\% when closing garment hem and hem\&neck. And for G9, the back VR decreased when closing garment apertures. Overall, the back VR at different aperture conditions were distinctly different according to different garment sizes and fabric permeability.

According to the above discussion, it was obvious that garments sizes and fabric permeability also affected the local VR under different garment apertures conditions. The IM garments had the smallest local VR at all conditions. For garments 170, the better the fabric permeability, the higher the local VR. While for garments 175 and 180, the semi-permeable always had the biggest local VR. Thus it can be concluded from Figure 5 that for garments with small microclimate volume (size 170), the local VR were positive correlated with the fabric permeability. But for garments with big microclimate volume (size 175 and 180), the local VR were impacted more by the fabric drapability. 


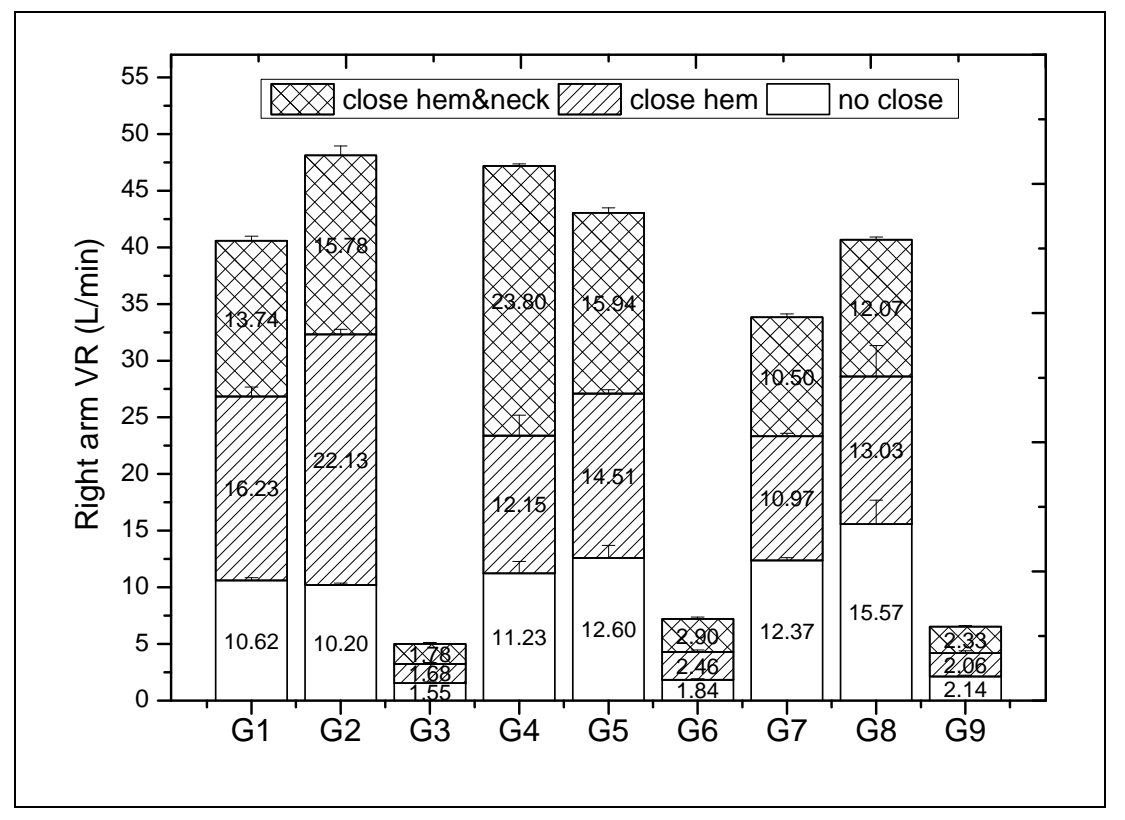

(a)

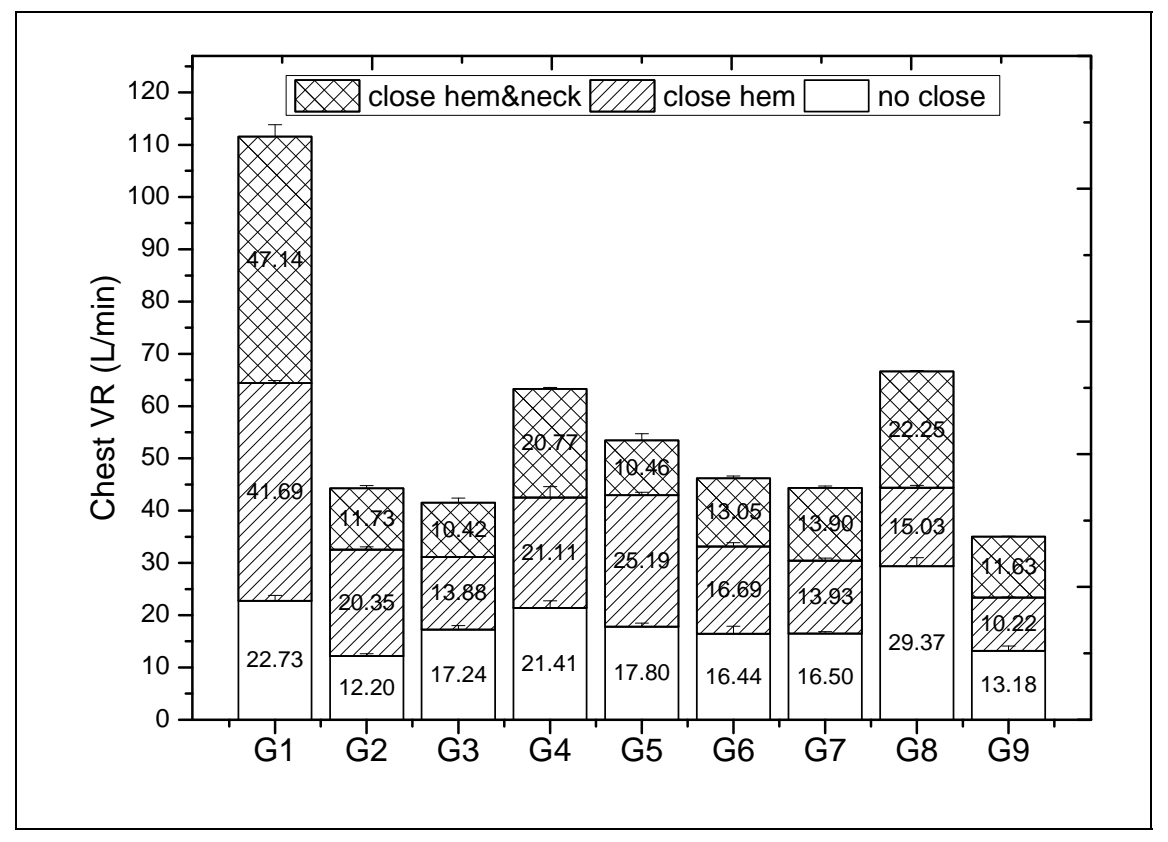

(b) 


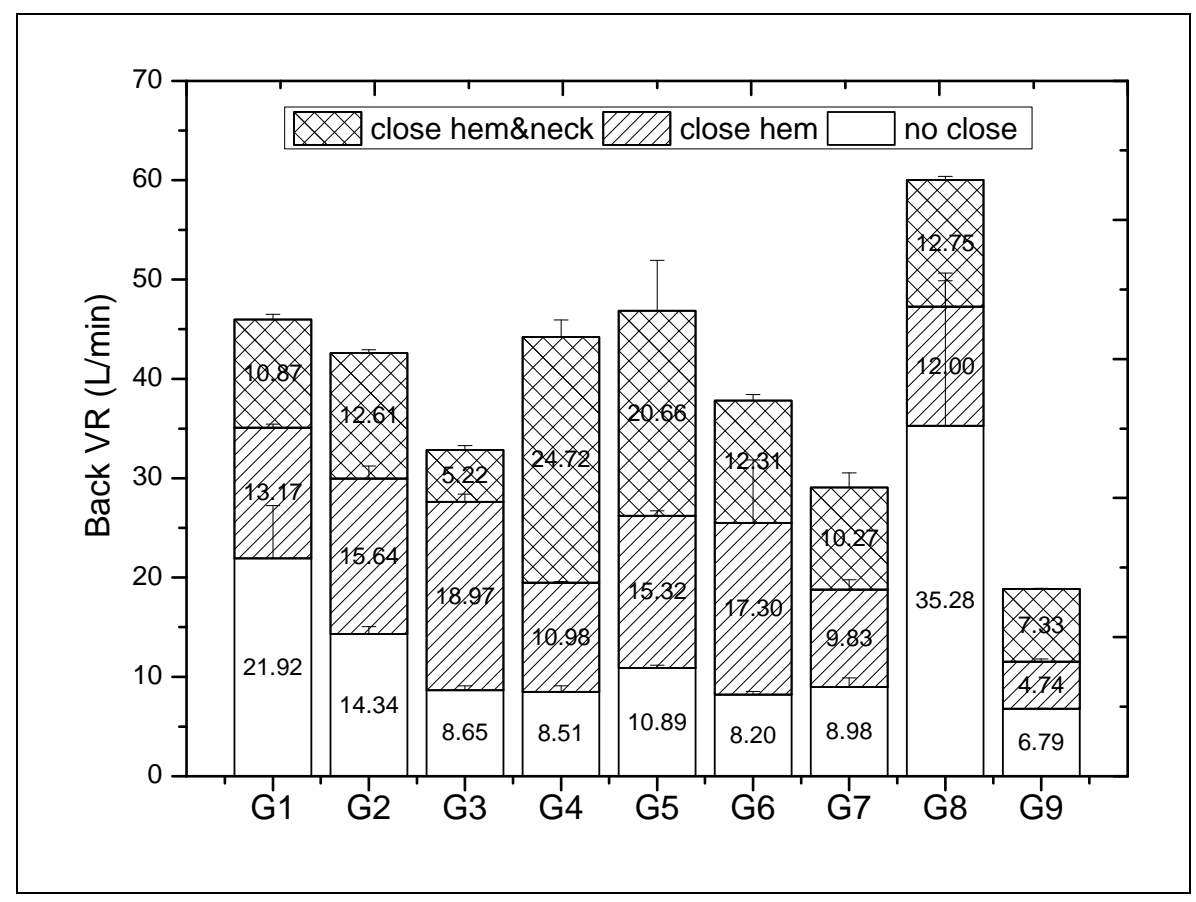

(c)

Figure 7. The local VR of the right arm (a), the chest (b) and the back (c) of the experimental garments at different garment aperture conditions.

G1: 170-PM; G2: 170-SM; G3: 170-IM; G4: 175-PM; G5: 175-SM; G6: 175-IM; G7-180-PM; G8: 180-SM; G9: 180-IM; VR: ventilation rates

Effects of clothing apertures on the local TI. Figure 8(a) shows the right arm TI of the 9 jackets at different garment aperture conditions. For PM garments, the right arm TI decreased at close hem except G4. While the local TI increased at close hem\&neck. For SM garments, closing garment hem or hem\&neck increased the local TI except at close hem\&neck of G2. The reason maybe that closing garment hem and neck decreased the air flow through garment apertures and thus increased the right arm TI. But for garment 170, the air exchange through hem or neck was less than other sizes, and meanwhile closing garment apertures decreased the microclimate volume. For IM garments, the situations were much complicated. For G3, closing garment apertures 
decreased the right arm TI. But for G6 and G9, closing hem increased the local TI. And closing hem\&neck decreased the TI for G6 while it increased the TI for G9. Therefore we can conclude that garment size impacted the impermeable garments more than it on the permeable and impermeable garments.

The Chest\&back TI of the 9 jackets at different apertures were presented in Figure 8(b). For PM garments, closing garment apertures decreased the local TI. For SM garments, closing garment apertures also decreased the local TI except at close hem of G2. The reason maybe that for garment 175, the microclimate volume increased when closing garment hem. This was impacted by fabric strength. While for IM garments, the situations were also much complicated. For G3, the local TI decreased when closing garment apertures. For G6, the local TI increased when closing hem only but it decreased when closing both hem and neck. The local TI increased when closing garment apertures for G9.

Therefore, closing garment apertures affected the right arm and the chest\&back TI significantly. But the effects of closing apertures on the local TI were also different according to different garment sizes and fabric permeability. The PM garments had the biggest chest\&back TI. We calculated the average local TI of different garment sizes and found that the garments 180 had the largest local TI. 


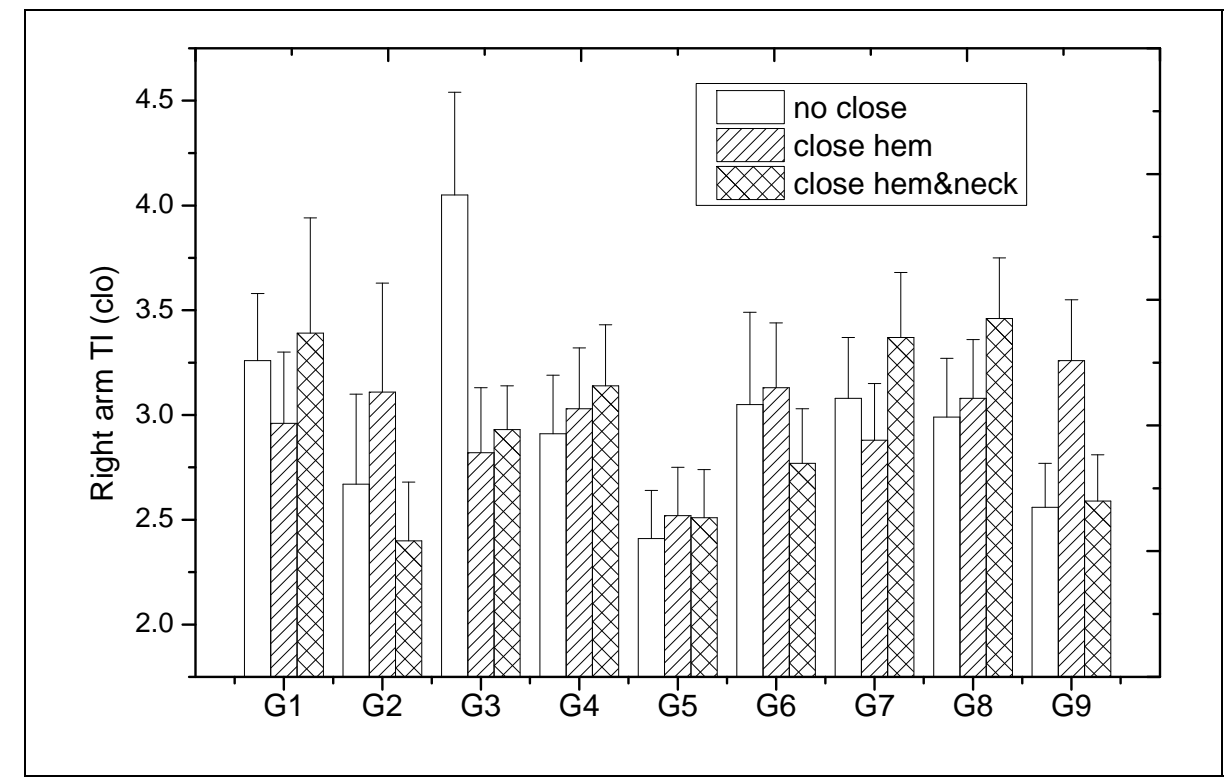

(a)

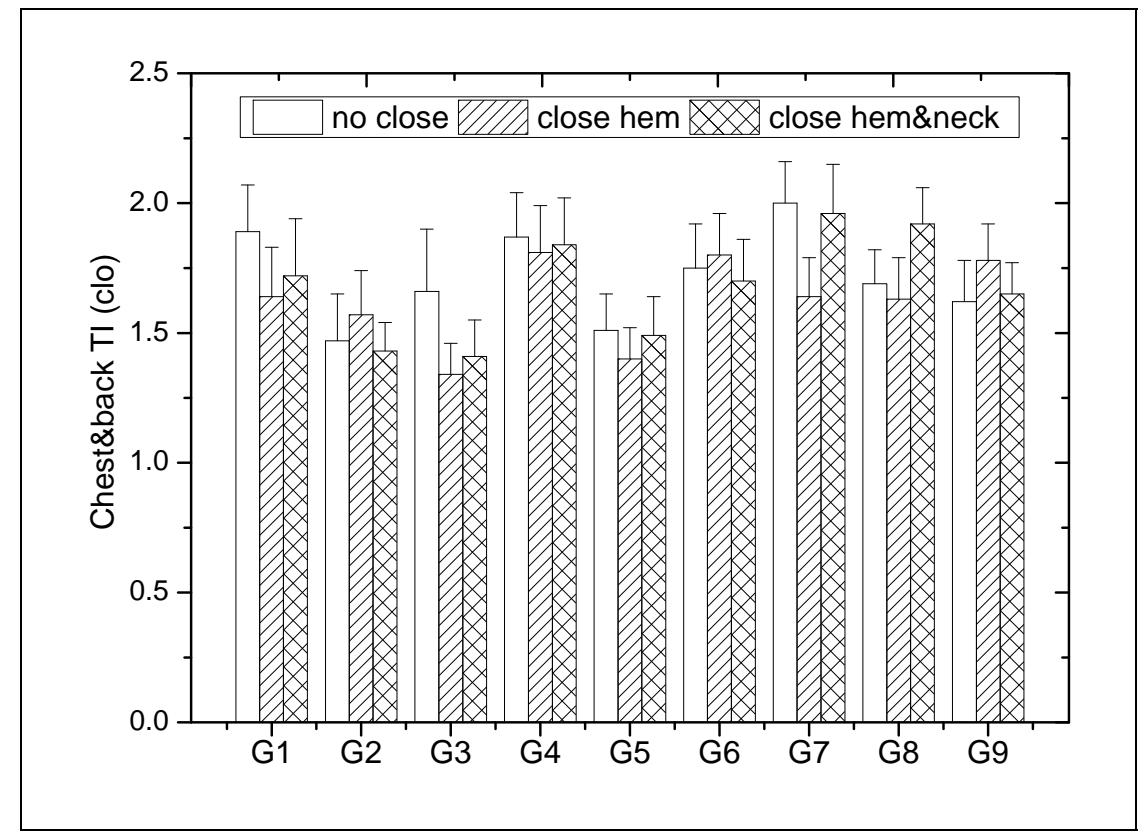

(b)

Figure 8. The local TI of the right arm (a) and the chest\&back (b) at different garment aperture conditions of the experimental jackets.

G1: 170-PM; G2: 170-SM; G3: 170-IM; G4: 175-PM; G5: 175-SM; G6: 175-IM; G7-180-PM; G8: 180-SM; G9: 180-IM; TI: thermal insulation 


\section{The combined effects of wind and clothing apertures on the local VR and TI}

The combined effects of wind and clothing apertures on the local VR. As was shown in Figure 9(a), the right arm VR increased when closing garment hem or hem\&neck in wind. The IM garments had the smallest VR at all conditions. Right arm VR at 1.1-hem were the largest, followed by 1.1-hem\&neck, 0-no close.

Figure 9(b) illustrated the chest VR under the combined effects of wind and apertures. Overall, closing garment hem in wind increased the chest VR except G3. The chest VR decreased by 13.3\% when closing hem for G3. The reason was that for IM garment of 170, closing the hem decreased the chest air exchange, and meanwhile the head-on wind decreased the chest microclimate volume. Closing garment hem and neck in wind also increased the chest VR except G1, G4 and G6. The chest VR decreased by $8.77 \mathrm{~L} / \mathrm{min}, 1.12 \mathrm{~L} / \mathrm{min}$ and $2.21 \mathrm{~L} / \mathrm{min}$ at 1.1-hem\&neck for G1, G4 and G6 respectively.

For back VR under the combined effects of wind and apertures (Figure 9(c)), closing garment apertures in wind also increased the local VR except G1 and G8. For G1, the back VR decreased at 1.1-hem while it increased at 1.1-hem\&neck. While for G8, the back VR decreased when closing garment apertures in wind.

Overall, closing garment hem in wind increased the local VR. But when closing both hem and neck in wind, the situations were much complicated. The local VR were impacted by the changed microclimate volume, the changed air exchange through fabric and the changed air exchange between locations. 


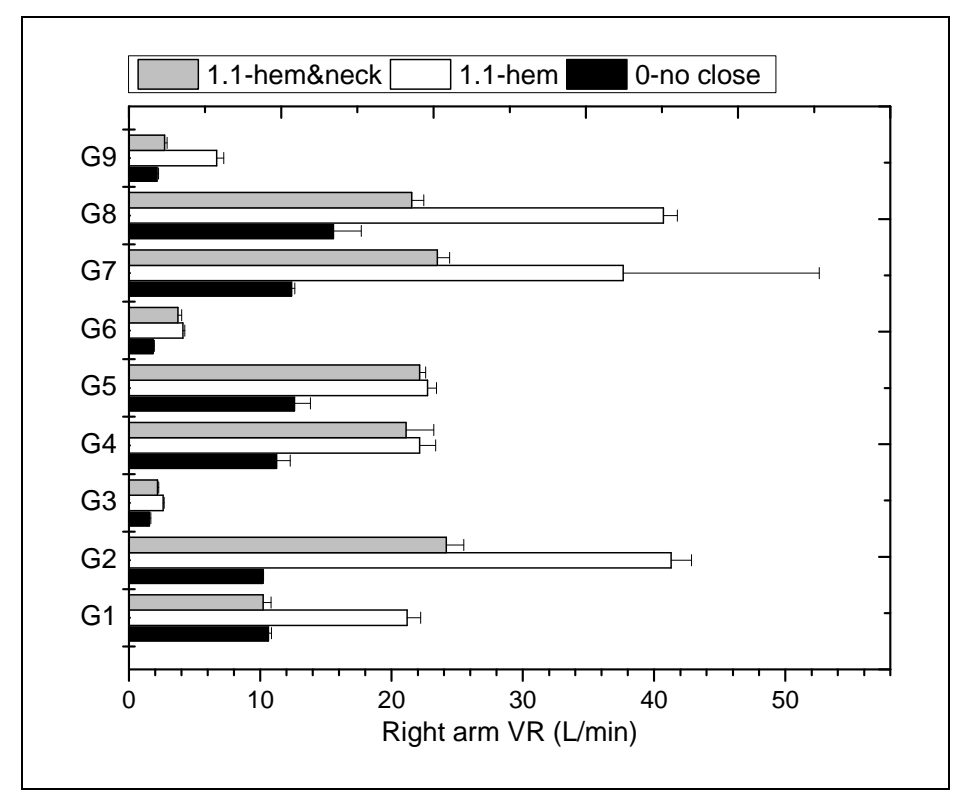

(a)

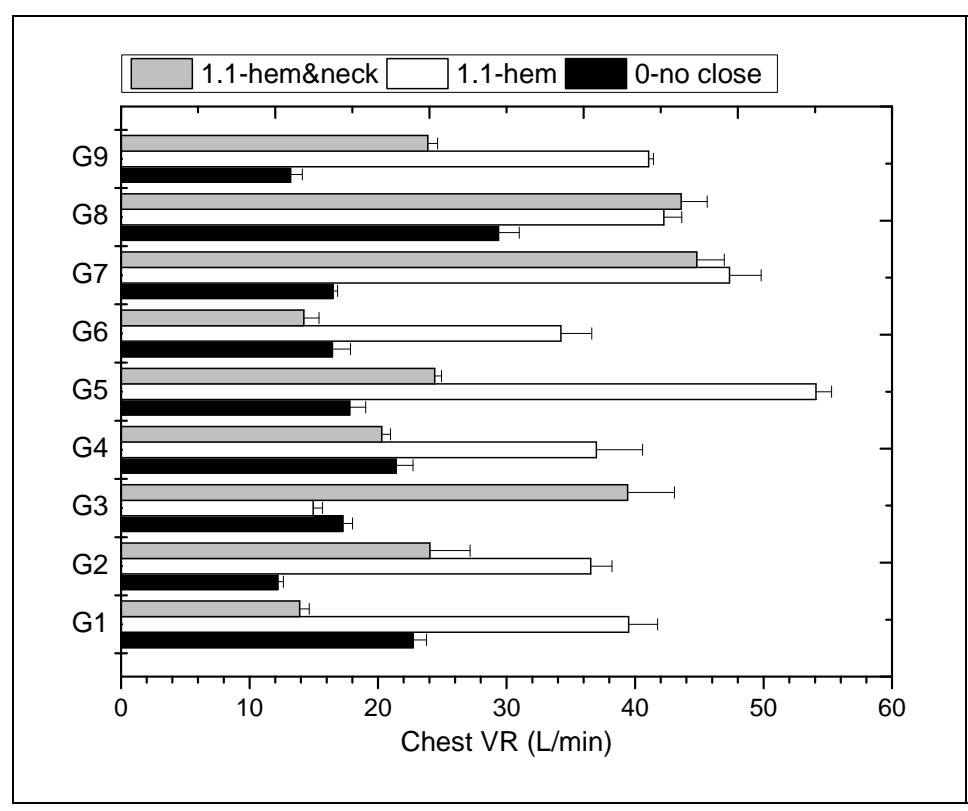

(b) 


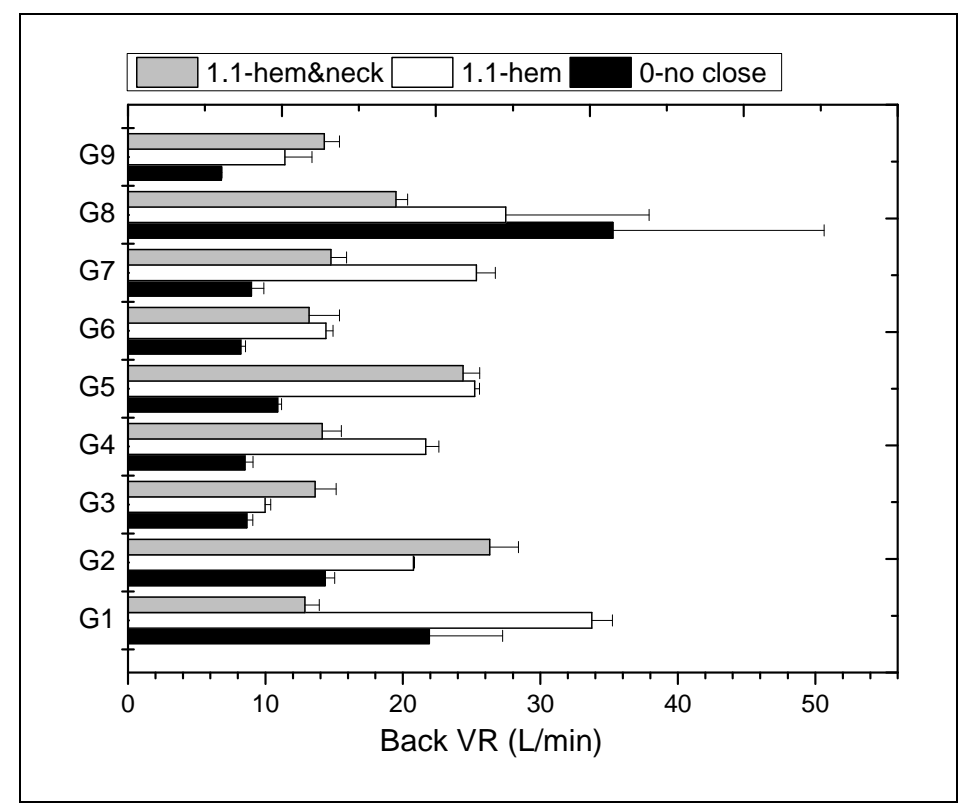

(c)

Figure 9. The local VR of the right arm (a), the chest (b), and the back (c) under the combined effects of wind and garment apertures.

G1: 170-PM; G2: 170-SM; G3: 170-IM; G4: 175-PM; G5: 175-SM; G6: 175-IM; G7-180-PM; G8: 180-SM; G9: 180-IM; VR: ventilation rates; 0-no close: no wind-no close; 1.1-hem: $1.1 \mathrm{~m} / \mathrm{s}$ wind speed-close garment hem; 1.1-hem\&neck: $1.1 \mathrm{~m} / \mathrm{s}$ wind speed-close garment hem and neck

The combined effects of wind and clothing apertures on the local TI. As was presented in Figure 10(a), the right arm TI were the largest at 0-no close. This illustrated that the interactions of wind and aperture decreased the right arm TI. The right arm TI were smallest at 1.1-hem\&neck except G1. This was consistent with the right arm VR. Overall, closing garment hem or hem\&neck in wind decreased the right arm TI. And for garments with closed hem, closing garment neck also decreased the right arm TI.

Figure 10(b) showed the chest\&back TI under the combined effects of wind and garment apertures. The local TI at no-close were also the largest. Chest\&back TI at 1.1-hem were smallest except G2. 
This may be caused by the testing error. Therefore, it can be concluded that closing garment hem or hem\&neck decreased the chest\&back TI. While for garments with closed hem, closing neck increased the chest\&back TI.

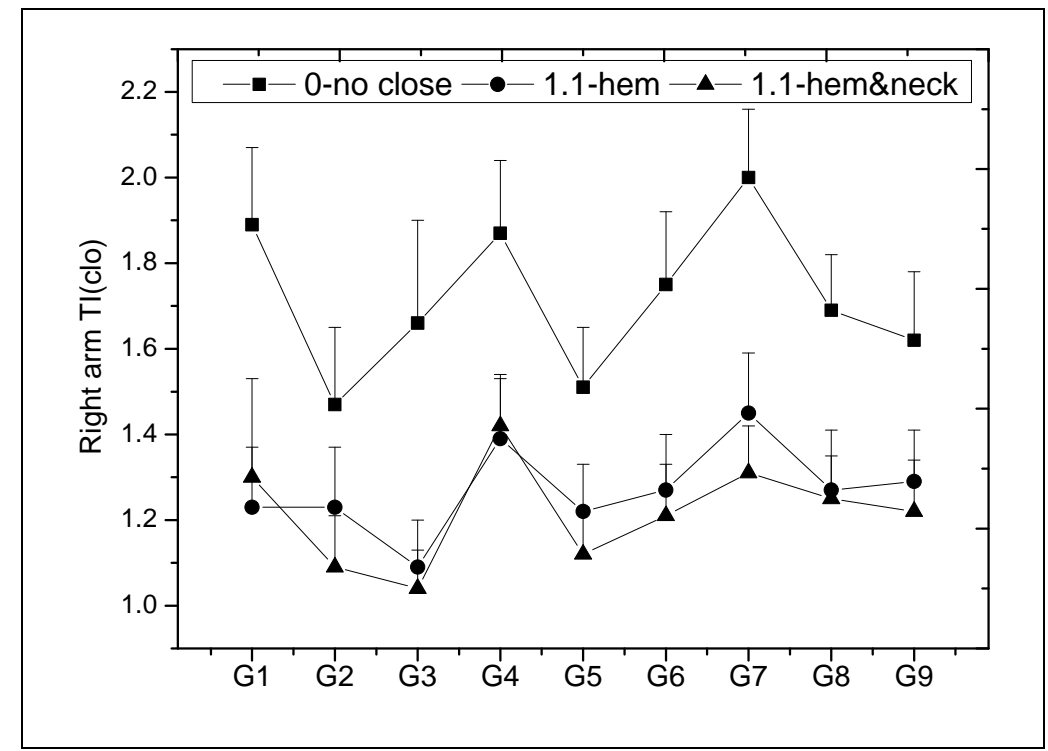

(a)

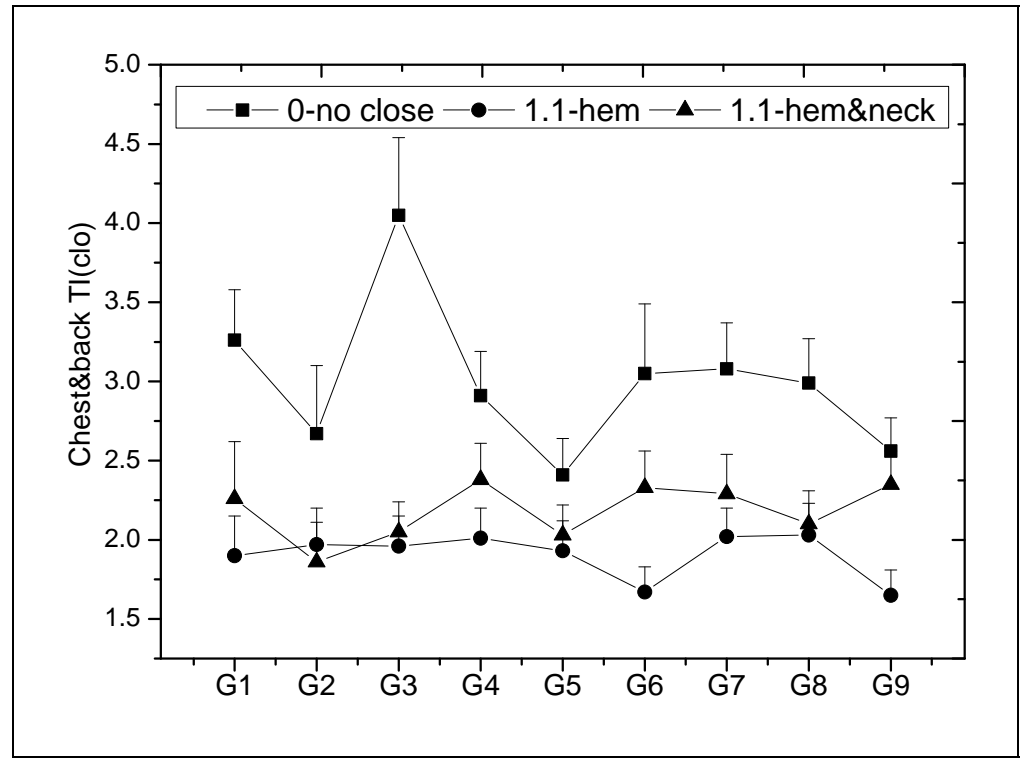

(b)

Figure 10. The local TI of the right arm (a) and the chest\&back (b) under the combined effects of wind and 
G1: 170-PM; G2: 170-SM; G3: 170-IM; G4: 175-PM; G5: 175-SM; G6: 175-IM; G7-180-PM; G8: 180-SM; G9:

180-IM; TI: thermal insulation; 0-no close: no wind-no close; 1.1-hem: $1.1 \mathrm{~m} / \mathrm{s}$ wind speed-close garment hem;

1.1-hem\&neck: $1.1 \mathrm{~m} / \mathrm{s}$ wind speed-close garment hem and neck.

\section{Conclusions}

An experimental study of effects of wind and garment apertures on the local VR and TI, of nine working jackets with different sizes and fabric permeability were conducted in this study.

For the tested samples, the experimental results showed that wind and garment apertures impacted the local VR and TI significantly. And the local VR and TI were also affected by garment sizes, fabric permeability and garment locations. For the local VR, the IM garments always had the smallest VR. But for PM and SM garments, the local VR were affected by both the fabric permeability and fabric drapability. The latter impacted more. For the local TI, the TI was positive correlated with the garment size except the IM garments. In addition, the head-on wind can change the local microclimate especially the chest microclimate obviously. This would change the local ventilation mechanism. Therefore, when choosing the working jackets, people should consider the fabric properties, especially the fabric permeability and drapability except for the garment size. And the windy conditions of the working place should also be considered.

\section{Funding}

This work was financially supported by the National Natural Science Foundation (51106022), Shanghai Pujiang Program, Innovation Program of Shanghai Municipal Education Commission (12ZZ068), and Doctoral Program of Higher Education of China 
(20110075120009/20110075110005).

\section{References}

1. Brinbaum RR, Crockford GW. Measurement of the clothing ventilation index. Appl Ergon 1978; 9: 194-200.

2. Lotens WA, Havenith G. Ventilation of rainwear determined by a trace gas method. Environ Ergon 1988; 34: 162-175.

3. Havenith G, Heus R, Lotens WA. Clothing ventilation, vapor resistance and permeability index: changes due to posture, movement and wind. Ergonomics 1990; 33: 989-1005.

4. Havenith G, Heus R and Lotens WA. Resultant clothing insulation - a function of body movement, posture, wind, clothing fit and ensemble. Ergonomics 1990; 33: 67-84.

5. Holland EJ, Wilson CA, Laing RM, et al. Microclimate ventilation of infant bedding. Int J Cloth Sci Tech 1999; 11: 226-239.

6. Satsumoto Y, Havenith G. Evaluation of overall and local ventilation in diapers. Text Res J 2010; 80: 1859-1871.

7. Satsumoto Y, Takeuchi M, Havenith G. The effects of size factor of leather shoes on ventilation rate in shoes. The Fourth International Conference on Human-Environment System (ICHES 2011) 2011.pp. 499-504.

8. Bouskill L, Havenith G, Kuklane K, et al. Relationship between clothing ventilation and thermal insulation. AIHA J 2002; 63: 262-268.

9. Havenith G, Zhang P, Hatcher K, et al. Comparison of two tracer gas dilution methods for the determination of clothing ventilation and of vapor resistance. Ergonomics 2010; 53: 548-558.

10. Ueda H, Havenith G. The effect of fabric air permeability on clothing ventilation. Environmental Ergonomics - The Ergonomics of Human Comfort, Health and Performance in the Thermal Environment 2005. pp. 343-346.

11. Ueda H, Inoue Y, Havenith G. The influence of a back opening on clothing ventilation in rainwear. The 11th International Conference On Environmental Ergonomics; Ystad, Sweden 2005. pp. 411-415.

12. Havenith G, Nilsson H.O. Correction of clothing insulation for movement and wind effects, a meta-analysis. Eur J Appl Physiol 2004; 92: 636-640.

13. Ueda $\mathrm{H}$, Inoue $\mathrm{Y}$, Matsudaira $\mathrm{M}$, et al. Regional microclimate humidity of clothing during light work as a result of the interaction between local sweat production and ventilation. Int J Cloth Sci Tech 2006; 18: 225-234.

14. Crockford.GW, Crowder M, Prestidg SP. Trace gas technique for measuring clothing microclimate air exchange rates. Br J Ind Med 1972; 29: 378-386.

15. Wang F, Ferraro SD, Lin L, et al. Localised boundary air layer and clothing evaporative resistances for individual body segments. Ergonomics 2012; 55: 799-812.

16. Zhao M, Gao C, Wang F, et al. A Study on Local Cooling of Garments with Ventilation Fans and Openings Placed at Different Torso Sites. Int J Ind Ergonom 2013; 43: 232-237.

17. Ho C, Fan J, Newton E, et al. The effect of added fullness and ventilation holes in T-shirt design on thermal comfort. Ergonomics 2011; 54: 403-410.

18. GB/T 1335.1: 1997.Size designation of clothes - Men.

19. Li J, Guo X, Wang Y. Temperature rating prediction of Tibetan robe ensemble based on different wearing ways. Appl Ergon 2012; 43: 909-915. 
20. Wang Y, Huang Z, Lu Y, et al. Heat transfer properties of the numerical human body simulated from the thermal manikin. $J$ Text Inst 2013; 104: 178-187.

21. ISO 9920: 2007. Ergonomics of the thermal environment - Estimation of thermal insulation and water vapor resistance of a clothing ensemble.

22. Dai X, Havenith G. Effect of clothing ventilation on thermal insulation and vapor resistance. In Proceedings of the 13th International Conference on Environmental Ergonomics. Boston, USA 2009:83-88.

23. Zhang Z, Wang Y, Li J. Mathematical simulation and experimental measurement of clothing surface temperature under different sized air gaps. Fibers Polym 2010; 11: 911-916.

24. Chen Y, Fan J, Qian X, Zhang W. Effect of garment fit on thermal insulation and evaporative resistance. Text Res $J$ 2004; 74: 742-748. 